\title{
Periodic Trends Transition Metal Sulfide Catalysis: Intuition and Theory
}

\author{
R.R. Chianelli ${ }^{1}$ \\ 1 Materials Research Technology Institute, University of Texas at El Paso, TX 79968 - USA \\ e-mail: chianell@utep.edu
}

\begin{abstract}
Résumé - Évolution des propriétés catalytiques en hydrodésulfurisation en fonction de la position du métal de transition dans la classification périodique : intuition et théorie - Le besoin d'hydrogéner du charbon afin d'obtenir des combustibles liquides devenant pressant dans les années 1920, des catalyseurs constitués de sulfure de métal de transition (TMS) ont été utilisés. Sabatier a reçu le prix Nobel en 1912 pour avoir décrit le phénomène d'hydrogénation par des métaux de transition. Cependant, lorsque les métaux de transition étaient utilisés pour hydrogéner du charbon, les TMS apparaissaient comme des états catalytiques stables en raison de leur teneur élevée en sulfure dans les liquides dérivés du charbon. À partir des années 1920-1930, I.G. Farbenindustrie A.G. a testé plus de 6000 catalyseurs. C'est à partir de là que le $\mathrm{Co}(\mathrm{Ni}) / \mathrm{Mo} / \mathrm{Al}_{2} \mathrm{O}_{3}$ moderne est apparu.

Depuis, les scientifiques nous ont permis de mieux comprendre les propriétés fondamentales qui conduisent à la fois à l'activité des sulfures binaires simples et au mécanisme par lequel deux métaux (Co + Mo) agissent de façon concomitante pour favoriser l'activité (promotion). Les efforts de départ se concentraient sur les catalyseurs commerciaux supportés avec un succès limité. Au début des années 1980, des évolutions des propriétés catalytiques en hydrodésulfurisation selon la position du métal de transition dans la classification périodique sur des catalyseurs non supportés, ont été découvertes et ces résultats sont à la base d'une compréhension basique supplémentaire des propriétés-clés qui ont conduit à l'activité catalytique. Ces résultats ont été enrichis de données complémentaires obtenues lors de recherches menées au fil des années afin d'inclure des catalyseurs supportés et de nombreux substrats à base de pétrole.
\end{abstract}

Des résultats précédemment obtenus reliaient l'activité catalytique aux chaleurs de formation des sulfures et au caractère $d$ (échelle de Pauling) des métaux de transition. Ces corrélations ont mis en évidence à la fois l'importance des électrons $4 d$ et $5 d$ mais également le principe catalytique bien établi selon lequel les liaisons du sulfure de métal nécessitaient d'être «juste bien établies», ni trop fortes ni trop faibles permettant ainsi une rotation facile des molécules d'adsorption et de désorption. La moyenne des chaleurs de formation de $\mathrm{Co}_{9} \mathrm{~S}_{8}$ et $\mathrm{MoS}_{2}$ suggérait que la promotion se produisait à travers les lacunes laissées par le sulfure et que la formation était réalisée par les atomes qui partageaient à la fois un atome Co et un atome Mo sur la surface.

Des études théoriques ont également commencé à cette période qui renforçaient encore plus l'idée que les électrons $d$ se trouvant dans les orbitales frontières des catalyseurs avaient un rôle-clé pour déterminer la catalyse à la surface. Le succès de cette approche s'explique par le fait qu'elle unifiait les systèmes de TMS promus avec les TMS binaires et offrait une logique commune pour les deux activités. Des progrès 
constants depuis lors ont été réalisés à travers l'application de la théorie fonctionnelle de la densité (DFT) réduisant l'écart entre l'instinct et une description formelle de la structure/fonction du catalyseur.

Pour une compréhension réelle dans le cadre de développements futurs, il est très important de se rappeler que nous devons étudier les matériaux catalytiquement stabilisés et non les matériaux qui changent selon les conditions catalytiques. Dans le cas des TMS, cela signifie que nous devons étudier des matériaux comme $\mathrm{MoS}_{2-\mathrm{x}} \mathrm{C}_{\mathrm{x}}$ et $\mathrm{RuS}_{2-\mathrm{x}} \mathrm{C}_{\mathrm{x}}$. Il a été démontré que les « carbures de surface » présentent un état catalytiquement stabilisé dans des conditions d'hydrotraitement. La relation originelle entre les électrons $d$ et les calculs DFT ultérieurs mettent tous en évidence l'importance de ces électrons dans la réaction catalytique. Cependant, des travaux supplémentaires sont nécessaires pour définir la relation entre ces électrons et les surfaces de carbure stabilisées avant que des structures détaillées de « site actif» ne puissent être développées en toute confiance. De plus, la présence de métal Co dans des catalyseurs d'hydrotraitement actifs stabilisés pour quatre ans dans un réacteur commercial, amène à s'interroger sur les théories actuelles de la structure des catalyseurs promus.

\begin{abstract}
Periodic Trends Transition Metal Sulfide Catalysis: Intuition and Theory - The use of Transition Metal Sulfide (TMS) catalysts came about as the need to hydrogenate coal to liquid fuels became urgent in the 1920's. Sabatier won the Nobel Prize in 1912 for describing the phenomenon of hydrogenation by transition metals. However, when the transition metals were used to hydrogenate coal, the TMS emerged as the stable catalytic states due to high sulfur content in the coal liquids. From 1920-1930 I.G. Farbenindustrie A.G. tested over 6000 catalysts. It was from these origins that modern $\mathrm{Co}(\mathrm{Ni}) / \mathrm{Mo} / \mathrm{Al}_{2} \mathrm{O}_{3}$ arose.
\end{abstract}

Since that time scientists have developed an understanding of the fundamental properties that lead to both the activity of the simple binary sulfides and the mechanism by which two metals (Co+Mo) acted together to enhance activity (promotion). Initial efforts focused on supported commercial catalysts with limited success. In the early 1980's the periodic trends of TMS catalysts on unsupported catalysts were discovered and these results formed the foundation for further basic understanding of the key properties that led to catalytic activity. These results have been extended over the years to include supported catalysts and many petroleum based substrates.

Early results related catalytic activity to the heats of formation of the sulfides and Pauling \% d-character of the transition metals. These correlations both pointed to the importance of the $4 d$ an $5 d$ electrons and also to the well established catalytic principle that the metal sulfur bonds needed to be "just right", not too strong nor too weak thus allowing facile turnover of the adsorbing and desorbing molecules. Averaging of the heat of formation of $\mathrm{Co}_{9} \mathrm{~S}_{8}$ and $\mathrm{MoS}_{2}$ suggested that promotion operated through sulfur vacancies formed by atoms that shared both a Co atom and a Mo atom on the surface.

Theoretical studies also began in this period that further supported the idea that d-electrons in the frontier orbitals of the catalysts were key in determining catalysis at the surface. The triumph of this approach was that it unified the promoted TMS systems with the binary TMS and provided a common rational for the activity of both. Constant progress since then has been achieved through the application of density functional theory (DFT) narrowing the gap between instinct and a formal description of catalyst structure/function.

It is crucial to remember that for real understanding to develop we must study the catalytically stabilized materials and not materials that are changing under catalytic conditions. In the case of the TMS this means that we must study materials like $\mathrm{MoS}_{2-x} C_{x}$ and $\mathrm{RuS}_{2-x} C_{x}$. It has been demonstrated that "surface carbides" are the catalytically stabilized state under hydrotreating conditions. The original relation between the d-electrons and later DFT calculations all point to the importance of these electrons in the catalytic reaction. However, more work is needed to define the relation between these electrons and the stabilized carbide surfaces before detailed "active site" structures can be developed with confidence. In addition the presence of Co metal in active hydroprocessing catalysts stabilized for four years in a commercial reactor, calls in to question current theories of the structure of promoted catalysts. 


\section{INTRODUCTION}

Paul Sabatier winner of the 1912 Nobel Prize in chemistry is considered by many as the "Father of Modern Catalysis" [1]. He achieved this distinction by developing an understanding of catalysis that has guided the field to this day. The understanding that he developed is embodied in the Sabatier principle. The Sabatier principle states that optimum catalytic properties arise at the optimum surface coverage of reactants when the catalyst metal- reactant bond-strength achieves an optimum value. This means that for the maximum catalytic rate to be achieved the value of the reactant /catalyst bond strength must be "just right" not too strong (preventing desorption of the product) and not too weak (preventing adsorption of the reacting molecule). This has been termed the Goldilocks effect. The active sites can't be too hot or too cold, but "just right". This effect leads to the well-known volcano plots that occur through catalysis.



Figure 1

Periodic trends observed by Pecoraro and Chianelli [8] for the hydrodesulfurization of dibenzothiophene at $400^{\circ} \mathrm{C}$ (activity per millimole of metal).

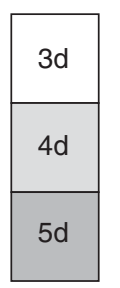

\begin{tabular}{|l|l|l|l|l|l|l|}
\hline $\mathrm{TiS}_{2}$ & $\mathrm{~V}_{2} \mathrm{~S}_{2}$ & $\mathrm{Cr}_{2} \mathrm{~S}_{2}$ & $\mathrm{MnS}$ & $\mathrm{FeS}_{\mathrm{x}}$ & $\mathrm{Co}_{9} \mathrm{~S}_{8}$ & $\mathrm{Ni}_{2} \mathrm{~S}_{3}$ \\
\hline $\mathrm{ZrS}_{2}$ & $\mathrm{NbS}_{2}$ & $\mathrm{MoS}_{2}$ & $\mathrm{TeS}_{2}$ & $\mathrm{RuS}_{2}$ & $\mathrm{Rh}_{2} \mathrm{~S}_{3}$ & $\mathrm{PtS}$ \\
\hline $\mathrm{HfS}_{2}$ & $\mathrm{TaS}_{2}$ & $\mathrm{WS}_{2}$ & $\mathrm{ReS}_{2}$ & $\mathrm{OsS}_{\mathrm{x}}$ & $\mathrm{IrS}_{\mathrm{x}}$ & $\mathrm{PtS}_{2}$ \\
\hline
\end{tabular}

Figure 2

The bulk catalytic stable states observed by Pecoraro and Chianelli [8] for the hydrodesulfurization of dibenzothiophene at $400^{\circ} \mathrm{C}$.
Sabatier's development and application of this principle, done without modern characterization and theoretical techniques, was a monumental achievement. Sabatier fully deserved the Noble Prize for this achievement but it was his use of this principle on industrial applications that revolutionized many industries and thus, our modern way of life. In his time Sabatier made practical adavnces in Ni hydrogenation catalysts, identified catalyst poisons and introduced catalyst supports. These discoveries led to major industrial advances in the margarine, oils and methanol industries. Further advances in catalysis based on the Sabatier principle subsequently occurred that had a major impact on twentieth century industry and individual life style, particularly in the emerging hydrocarbon based transportation industry.

Another Nobel Prize in 1913 for the hydrogenation of coal and heavy petroleum using molecular hydrogen was given to Bergius [2]. This discovery revolutionized the chemical industry and prepared the way for the introduction of mobile warfare that dominated the first half of the twentieth century. Thus, began a race to convert coal and heavy petroleum into useful fuels and chemicals through application of the principles of catalysis. It was with confidence from the earlier success in ammonia synthesis and other areas that the work proceeded. However, it was quickly discovered that the transition metals were converted to TMS (transmission metal sulfide) catalytic materials in the sulfur rich coal and heavy petroleum. It was from these beginnings that the field of TMS catalysis emerged. In this period over 6000 catalysts where tested by IGF (I.G. Farbenindustrie A.G.) and BASF (Badische Anilin u. Sodafabrik). Particularly, important was the work of Pier [3]. It was from this work that $\mathrm{MoS}_{2}$ and $\mathrm{WS}_{2}$ TMS catalytic materials became the basis of the modern Co or Ni promoted, alumina supported catalyst. The work in TMS catalytic materials is thoroughly reviewed up to 1973 in the classic book by Weisser and Landa [4]. Fundamental aspects of our understanding of the TMS catalytic materials after 1973 has been recently reviewed [5]. Both these references underline the essential point of this article. In order to develop fundamental understanding of the TMS catalytic materials the catalysts must be studied in their Stabilized Catalytic State. This is too often ignored in recent literature leads to results that are not related to real catalyst behavior.

\section{THE BULK CATALYTIC STABLE STATES OF THE BINARY TRANSITION METAL SULFIDES}

Following earlier work of Sinfelt in ethane hydrogenolysis [6], we decided in the late 1970's to study the periodic effect in the HDS (hydrodesulfurization) using TMS catalytic materials. This involved making all the TMS catalysts with high surface area in a sulfided state. A method was developed using transition metal halide non-aqueous precipitation with 
lithium sulfide [7]. This method provided a uniform synthesis across the periodic table with catalysts having reasonable surface areas in the range of $40-90 \mathrm{~m}^{2} / \mathrm{gm}$. All the TMS catalysts were prepared with the exception of $\mathrm{TcS}_{2}$ which is radioactive. The catalysts prepared in this manner were then activity tested in DBT (dibenzothiophene) in a decalin solvent at $35 \mathrm{kPa}$ (450 psig) of hydrogen between 300 and $400^{\circ} \mathrm{C}$ [8]. A classical volcano plot emerged as shown in Figure 1 for the $\mathrm{HDS}$ of DBT at $400^{\circ} \mathrm{C}$.

The activity test generally took from 4 to 8 hours depending on the catalyst and the temperature of the catalytic reaction. In some cases (Fe, Os, Ir) the catalytic TMS materials changed their bulk structure during the activity measurement period. The catalytically stabilized bulk crystal structures are shown in Figure 2. Os changed from the starting layered $\mathrm{OsS}_{2}$ to an amorphous mixture of Os metal and $\mathrm{S}$. In a similar manner Ir changed from $\mathrm{IrS}_{2}$ to an amorphous mixture of Ir metal and $\mathrm{S}$. It is important to note that when considering the origin of the catalytic activity in the TMS catalytic materials a stuctural change may occur from the precursor state and thus too much emphasis on the structure of the precursor state may lead to results that are not relevAnt to the observed catalytic activity.

The periodic results described above where later confirmed in several studies for HDS and other reactions. Similar trends were later observed for hydrogenation reactions and HDN (hydrodenitrogenation) [9-11]. These results were also extended to real feeds such as a heavy gas-oil [12]. Periodic effects on catalysts supported on carbon were studied by Vissers et al. [13] and Ledoux et al. [14]. These studies demonstrated again the effectiveness of the group VIII noble metals with only slight changes. The maximum of the volcano plot occurs at $\mathrm{Ru}$ and $\mathrm{Os}$ in this report and for $\mathrm{Rh}$ and $\mathrm{Ir}$ in the previously cited reports. This difference is most likely attributable to dispersion effects. In the case of the supported catalyst it is difficult to determine the surface area of the active TMS phase.

\section{EARLY CORRELATIONS TO ACTIVITY}

Because the stucture and stoichiometry of the stabilized catalyst varied greatly, general factors were investigated to develop correlations to catalytic activity. It was obvious that the $4 d$ and $5 d$ electrons played a central role in optimizing catalytic activity. Thus, it is not surprising that Pauling \% $d$-character plotted against activity yields a straight line as seen in Figure 3. Pauling's \% d-character represents the ability of the transition metals to bond co-valently with themselves. $\mathrm{Ru}, \mathrm{Rh}, \mathrm{Ir}$ and Os have the maximum ability to do this and they are the most active HDS catalysts. The ability of the $4 d$ and $5 d$ electrons of noble metals to self-bond reflects the high degree of covalency inherent in these metals and this is a fundamental property of active heterogenous catalytic materials. It is the property of these metals that gives rise to the surface properties that create the active catalytic sites. These sites interact with the reacting molecule and thus, the bulk electronic stucture correlates to the catalytic activity. In addition, they retain their basic electronic properties regardless of the catalytic environment although the formal oxidation state may change. The Pauling \% d-character after much work still remains one of the best correlations to the catalytic activity of the the TMS catalysts, best reflecting the key element in correlating the properties of materials to their cat-

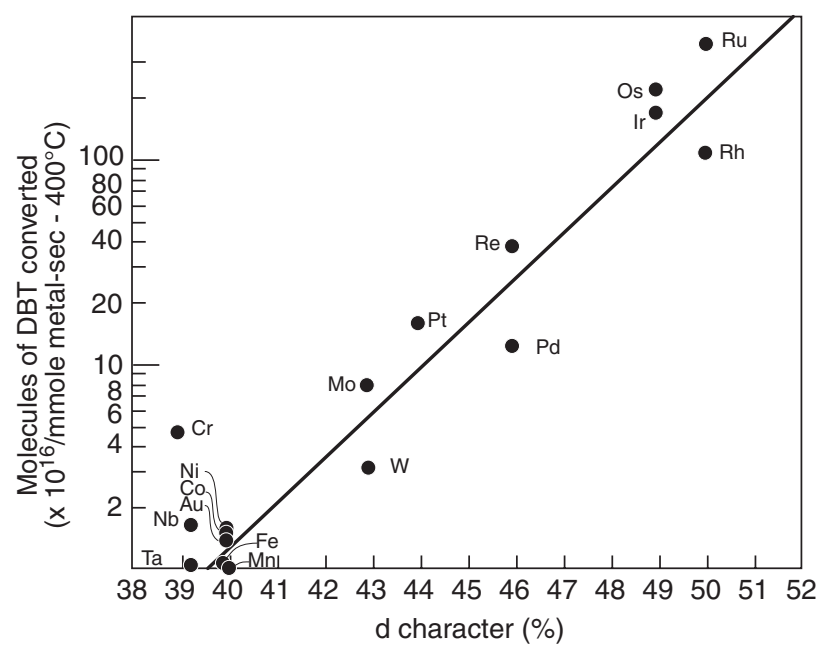

Figure 3

Pauling's $\% d$-character plotted against the hydrodesulfurization of dibenzothiophene at $400^{\circ} \mathrm{C}$ [8].

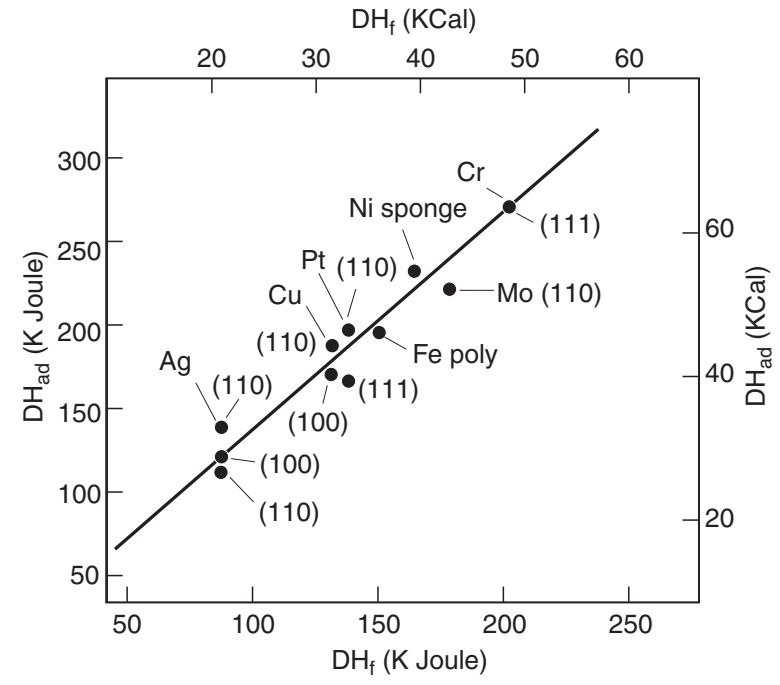

Figure 4

Heat of adsorption of sulfur on metals $v s$. heat of formation of sulfides [15]. 
alytic actvity, the electronic properties of the transition metal. The $4 d$ and $5 d$ electrons in the group VIII metals have the ability to facilitate catalytic activity in a changing catalytic environment, stabilizing the appropriate surface states as the catalytic environment changes. Thus, the precise nature of the surface state will change as the catalytic enviroment changes, for example as the hydrogen pressure varies, but the ability to catalyze the reaction remains constant. This is the most fundamental aspect of catalysis by the TMS.

\section{SABATIER'S PRINCIPLE APPLIED TO THE TMS}

The appearance of the volcano curves described above immediately led to the application of Sabatier's priciple to to the TMS catalysts. Bernard et al. [15] had shown a linear relation between the heat of adsorption of sulfur on the transition metals and the heat of formation of the TMS as shown in Figure 4. This suggested that the binding of reacting sulfur molecules at the surface would be determined by a bulk property such as the heat of formation of the TMS. The sulfur-containing molecule would be bound too strongly by transition metals on the left of the periodic table and too weakly on the right side of the periodic table. The TMS sulfides in the middle of the periodic table would bind the sulfur-containing molecule with just the right strength to allow facile turnover in the HDS reaction, thus Sabatier's principle. This classic relation is shown in Figure 5. An optimum value between $29-55 \mathrm{kcal} / \mathrm{mol}$ was observed for the optimum value. It was recognized at the time that this correlation was inadequate for two reasons. The first was the variable of the stabilized catalytic phases and the second was that the fit was only approximate in ordering the observed catalytic activity.
However, the heat of formation of the TMS correlation to HDS activity has a serious drawback. MnS has a heat of formation $(51 \mathrm{kcal} / \mathrm{mol})$ very close to that of $\mathrm{RuS}_{2}(49 \mathrm{kcal} / \mathrm{mol})$ and yet $\mathrm{RuS}_{2}$ is the most active TMS and MnS is the least active. The result emphasizes the importance of the $4 d$ and $5 d$ electrons in HDS catalysis. It was recognized that the desirable property for correlation was the TM/S bond strength which is itself correlated to the TMS heat of formation, but at the time of the original work this was very difficult to obtain. The later development of the DFT (density functional theory) computational technique made calculation of the TM/S much easier and they were calculated for the first time by Toulhoat, Raybaud and co-workers [16, 17]. They derived the TM/S from the experimental cohesive energy obtained by adding the heat of sublimation of the elements to the heat of formation of the compounds. The TM/S bond strength is that fraction of the total cohesive energy of the compound that can be assigned to this particular bond. This method is straight forward keeping in mind that assumptions must be made for the elements Os and Ir which occur in the amorphous states in their catalytically stable states. Nevertheless the volcano curves that result give better correlation to the HDS activity as seen in Figure 6 . The TM/S correlation now accounts for the first row TMS activity. $\mathrm{Cr}_{2} \mathrm{~S}_{3}$, $\mathrm{MnS}$ and VS have experimental TM/S bond energies (respectively 80,51 and $68 \mathrm{kcal} / \mathrm{mol}$ ) quite different from their heat of formation (respectively 46, 31 and $43 \mathrm{kcal} / \mathrm{mol}$ ). The maximum for the volcano plots shown in Figures 5 and 6 are both normalized to activity $/ \mathrm{m}^{2} \cdot \mathrm{s}$ and they are very similar with $\mathrm{Ru}, \mathrm{Rh}$, Os and Ir grouped at the peak with activities significantly higher than the remaining TMS. This emphasizes that until better active site measurements are available further discussion of which TMS is most active is premature.

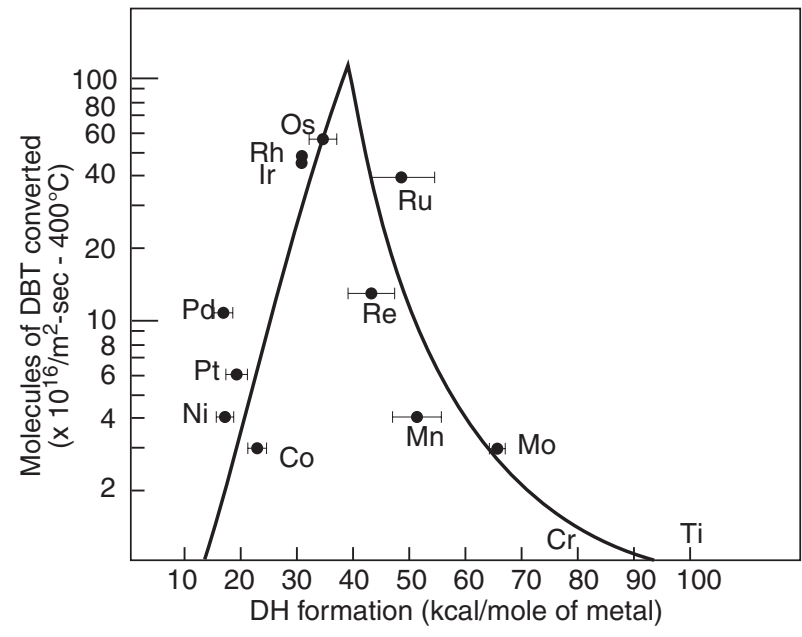

Figure 5

HDS activity of the TMS $v s$. the heat of formation of the transition metal sulfides [25].

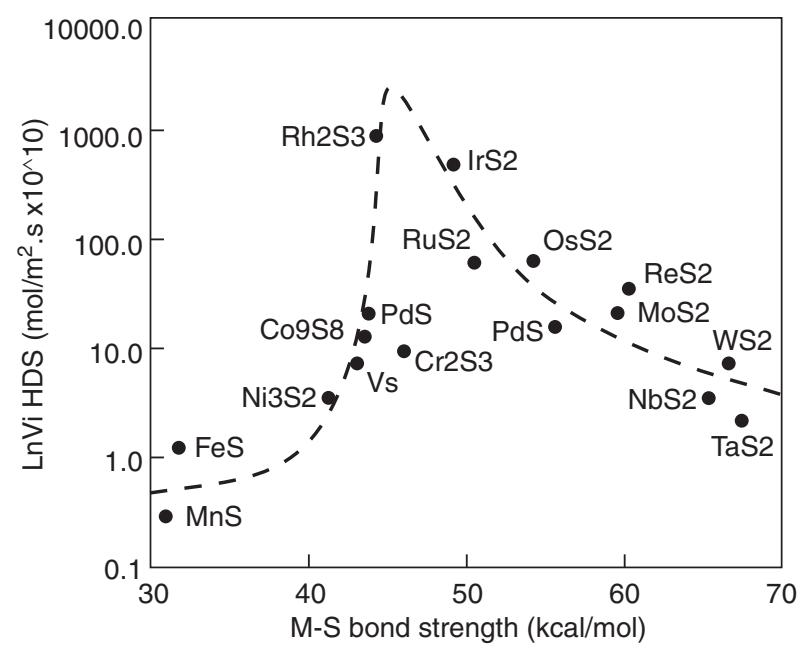

Figure 6

HDS activity of the TMS vs. the bond strength of the transition metal sulfides [17]. 
The important question remains: what is the relation between the bulk TM/S bond strength and the surface TM/S bond strengths? Toulhoat and Raybaud [18] answered this question by applying the Brønsted/Evans/Polanyi free energy relationship to the binary TMS, developing a linear relation between the bulk TM/S bond energy descriptor and the surface TM/S bond energy descriptor. Furthermore, they were able to relate experimental activities and selectivities as predicted by the bond energy descriptor, free energy and using a Langmuir/Hinshelwood rate expression. This completed the application of the DFT method to the binary TMS catalytic materials for the TMS in the purely sulfided state. However, we will see below that more work is required as we consider the stabilized catalytic states for both binary TMS and the synergic pairs.

\section{THE SYNERGIC EFFECT}

TMS catalysts are used because of their ability to perform a myriad of important reactions in the presence of sulfur and because they remain stable. The second and third row TMS such as $\mathrm{RuS}_{2}$ and $\mathrm{Rh}_{2} \mathrm{~S}_{3}$ are the most active and stable TMS catalysts. They are, however, very expensive and as a result have not found wide commercial application, though still retaining a great potential. Because of the cost and scarcity of the noble metals Mo and $\mathrm{W}$ based catalysts are preferred and used in every refinery in the world for hydrotreating reactions involving hydrogenation (Hyd), sulfur (HDS) and nitrogen (HDN) removal to meet environmental standards. Either Co, $\mathrm{Ni}$ or both are added to "promote" activity and the entire catalyst is supported on $\mathrm{Al}_{2} \mathrm{O}_{3}$. Generally, the promoter is added to achieve a $\mathrm{Co}(\mathrm{Ni}) /[\mathrm{Co}(\mathrm{Ni})+\mathrm{Mo}$ ] molar ratio of 0.3 [19]. When the promoter metal (Co or $\mathrm{Ni}$ ) is in this ratio with respect to the base metal (W or Mo) a significant increase in activity is achieved. The increase in activity varies according to details of preparation, materials and other factors, but generally can vary up to factors of 10 to 12 times the un-promoted activity. This is called the synergic effect implying that the two components, promoter and base metal act together.

Several explanations have been proposed to explain the origin of the synergic effect. Voorhoeve and Stuiver and Farragher and Cossee proposed a model derived from the structure of sulfides called pseudointercation [20, 21]. This model describes intercalation a short distance into the van der Waals layers of the lamellar $\mathrm{WS}_{2}$, by TMS of the first row of the periodic table $(\mathrm{Fe}, \mathrm{Co}, \mathrm{Ni})$ thus, pseudointercation. This results in electron transfer to the $\mathrm{WS}_{2}$, creating $\mathrm{W}^{+3}$. The promotion effect would result from a charge transfer from pseudo-intercalated $\mathrm{Ni}$ promoting atoms to $\mathrm{W}^{+3}$ sites. Promotion occurs because $\mathrm{W}^{+3}$ sites are more active than $\mathrm{W}^{+4}$ sites a fact, described below and confirmed theoretically. According to the Voorhoeve model, the active sites do not change in nature after Ni promotion, only their number increases via indirect electron transfer to the layers. This work introduced the notion of edge sites and electronic origin for promotion still important today.

Topsøe and co-workers using MES (Mössbauer emission spectroscopy) introduced the CoMoS phase concept. They showed that in a freshly prepared catalyst a particular Co environment led to the promoting effect, i.e. Co atoms decorate the edges of $\mathrm{MoS}_{2}$ layers forming the $\mathrm{Co}-\mathrm{Mo}-\mathrm{S}$ phase [22]. The $C o M o S$ phase was beautifully imaged at the atomic level using AFM (atomic force microscopy) [23]. In this work $\mathrm{Co}$ atoms bound to the edge of $\mathrm{MoS}_{2}$ triangular nano-particles and sulfur vacancies may be seen. This model demonstrates much insight into the nature of the interaction of the promoter metals (Co and $\mathrm{Ni}$ ) with the base $\mathrm{MoS}_{2}$ and $\mathrm{WS}_{2}$ catalysts. However, we now recognize as discussed in detail below that the $C o M o S$ phase does not survive under catalytic conditions and is thus, not a catalytically stabilized phase.

The above models describing the promoted or synergistic state can be further understood by looking at the "phase diagram" shown in Figure 7. This phase diagram describes the concept of symmetrical synergy [24]. This diagram describes the phase to be expected when unsupported catalysts are stabilized in DBT/Decalin at $400^{\circ} \mathrm{C}$ and $450 \mathrm{KPa} \mathrm{H}_{2}$ during a typical model compound HDS test. Starting on the left side of the diagram $\mathrm{MoS}_{2}$ has an initial activity that is enhanced (promoted) as Co is added presumably through edge decoration. This region is the focus of the $\operatorname{CoMoS}$ phase or edge decoration models described above. At the peak of the initial promotion curve addition of further amounts of Co leads to phase separation and lower surface. In this region two phases exist, $\mathrm{Co}_{9} \mathrm{~S}_{8}$ and $\mathrm{MoS}_{2}$. This is the region of contact synergy described by Delmon and co-workers [25]. Moving to the extreme right we arrive at the fact that Mo promotes $\mathrm{Co}_{9} \mathrm{~S}_{8}$ in much the same manner as Co promotes $\mathrm{MoS}_{2}$,

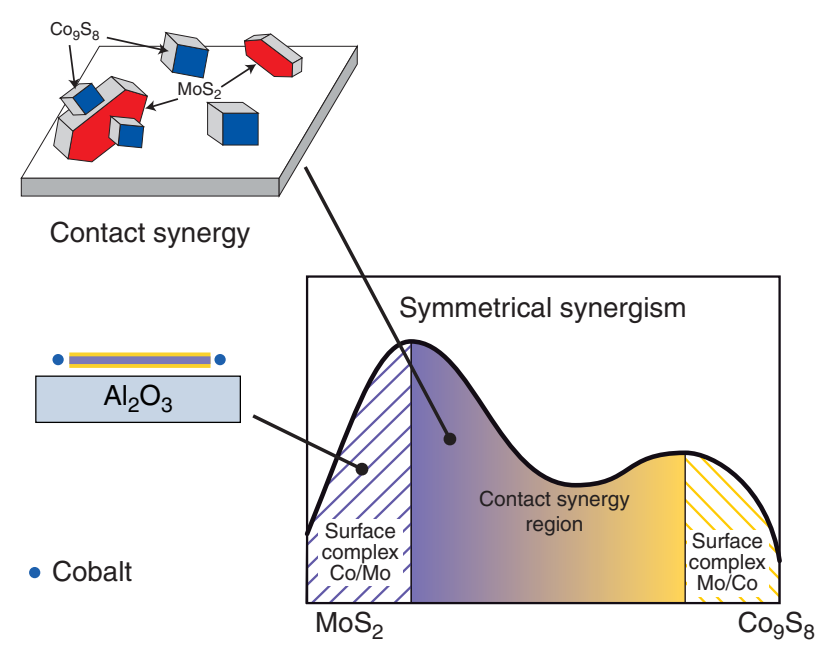

Figure 7

Symmetrical synergy [23]. 
thus, the term symmetrical synergism. This fact has been largely ignored in the literature and has been described as surface enrichment phases by Phillips and Fote in another largely ignored article [26]. The phenomenon described above are illustrated in Figure 7.

It was the existence of symmetrical synergism and surface enrichment phases of Phillips and Fote that led to a crucial concept in understanding of the promotion phenomenon. This phenomenon was termed pseudo-binary behavior and contained the idea that $\mathrm{MoS}_{2}$ and $\mathrm{WS}_{2}$ could be promoted through electron donation from Co or Ni. This occurs at the surface through the formations of a state in which sulfur atoms where shared [27]. pseudo-binary behavior also conformed to the Sabatier principle if one imagines the sulfursharing cluster creating vacancies that "mimic" noble metal behavior. Table 1 indicates the average heat of formation of the synergic pairs.

TABLE 1

The average heat of formation of the synergic pairs

\begin{tabular}{c|c}
\hline Synergic pair & $\begin{array}{c}\text { Average heat of formation } \\
\mathrm{kcal} / \mathrm{mol}\end{array}$ \\
\hline $\mathrm{Co}_{9} \mathrm{~S}_{8}+\mathrm{MoS}_{2}$ & 44.2 \\
$\mathrm{Co}_{9} \mathrm{~S}_{8}+\mathrm{WS}_{2}$ & 42.3 \\
$\mathrm{Ni}_{3} \mathrm{~S}_{2}+\mathrm{MoS}_{2}$ & 41.5 \\
$\mathrm{Ni}_{3} \mathrm{~S}_{2}+\mathrm{WS}_{2}$ & 39.6 \\
\hline
\end{tabular}

The application of the Sabatier principle leading to the average heat of formation of the synergic pairs suffers from a similar problem as the application of the heat of formation to the TMS as describe above. The problem being that all-possible combinations of the TMS are not included. Nevertheless this observation leads to the concept of pseudo-binary behavior that is the basis of modern electronic theory.

However, this concept was extended as before to the mean bond strength of the surface cluster. Synergic pairs arise when one TMS phase with bond strength less than $50 \mathrm{kcal} / \mathrm{mol}$ is mixed with another phase that has a bond strength greater than $50 \mathrm{kcal} / \mathrm{mol}$. This leads to a surface cluster with an average bond strength in the optimum range (39 $\mathrm{kcal} / \mathrm{mol}$ ) leading to pseudo-binary behavior and enhanced activity. This approach results in an extended suite of synergic pairs with potential practical application in many hydrotreating reactions [28].

The first explanation of promotion that involved the basic properties of the TMS $d$ electrons was that of Harris and Chianelli using the scattered wave SCF-X $\alpha$ calculations on non-neutral octahedral $\mathrm{MS}_{6}{ }^{\mathrm{n}-}$ clusters [29]. The filling of the $4 d$ orbitals from $\mathrm{Nb}$ to $\mathrm{Pd}$ is indicated in Figure 8. These calculations were later updated with current DFT by Raybaud $e t$ $a l$. [30]. The $4 d$ anti-bonding orbitals can be seen descending into the sulfur $3 p$ band as we move from $\mathrm{Nb}$ to $\mathrm{Pd}$. The most active catalysts $(\mathrm{Ru}, \mathrm{Rh})$ have the maximum number of

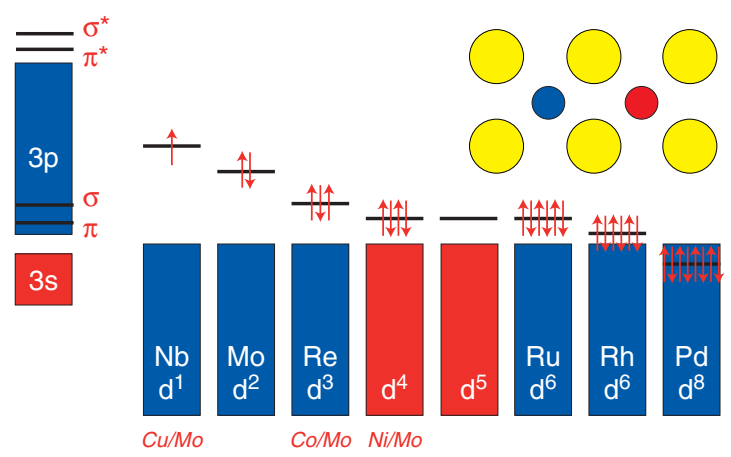

Figure 8

Electronic promotion: yellow atoms $=$ sulfur; red atoms $=$ molybdenum; blue atoms $=$ promoter $(\mathrm{Fe}, \mathrm{Co}, \mathrm{Ni}$ and $\mathrm{Cu})$.

$d$ electrons in these orbitals and the maximum covalent character. These properties of the catalyst were embodied in an activity parameter: $\mathrm{A}=n \mathrm{~B}$ (where $n=$ the number of $4 d$ or $5 d$ electrons and $\mathrm{B}$ is the degree of covalent character derived from the calculation). This activity parameter, though a simple idea, adequately described the electronic origin of the activity of the TMS catalysts.

However, the most important contribution of this work was to bind together the Synergic pairs with the binary TMS in one scheme. It was assumed that somewhere at the surface of the second row or third row TMS, such as $\mathrm{MoS}_{2}$, there was a "cluster" in which sulfurs where shared by the second row TMS and a first row TMS. Charge transfer would then occur between the two metals. The second or third row TMS would supply the $4 d$ or $5 d$ orbitals and the first row TMS would add or subtract electrons as indicated in Figure 8. For $\mathrm{MoS}_{2}$, starting with $\mathrm{Fe}$ no transfer was achieved but as one moved to $\mathrm{Co}$, one electron was donated to $\mathrm{MoS}_{2}$ making it iso-electronic with $\mathrm{ReS}_{2}$ increasing the activity. When the cluster was formed with $\mathrm{Ni}$, two electrons where added to $\mathrm{MoS}_{2}$ increasing the number of $4 d$ electrons in the $4 d$ orbitals and thus further enhancing the activity. In this case there is no analogous binary TMS. When arriving at $\mathrm{Cu}$ the situation changes. $\mathrm{Cu}$ achieves the $d^{10}$ configuration withdrawing one electron and leaving the $\mathrm{MoS}_{2}$ with the electronic configuration of $\mathrm{Nb}$. Thus Cu "poisons" the activity of $\mathrm{MoS}_{2}$. This effect was predicted by the theory before experimental verification proving the utility of the method in making predictions.

As stated above the original approach was oversimplified in many respects. Calculation of the octahedral cluster is obviously one of the serious oversimplifications. The TMS are semiconductors because of the strong bonding-anti-bonding splitting in the S $3 p \pi-\mathrm{TM} d$ band complex. This is directly related to the strong covalent character of the metal-sulfur bond. However, the width of the band cannot be used to predict the relative HDS activity of sulfides. Further description of the calculated octahedral clusters reveals that they contain the sulfur $3 p$ orbitals, the $2 e_{g}$ and $1 t_{2 g}$ orbitals 
that are the $\sigma$ and $\pi$ bonding orbitals. The $3 e_{g}$ and $2 t_{2 g}$ components are the anti-bonding counterparts of the bonding $2 e_{g}$ and $1 t_{2 g}$ orbitals. Using octahedral symmetry and varying the nature of the metal center across the periodic table, different electronic factors were found relevant in order to correlate electronic structures to HDS activity. These factors are: the number of $d$ electrons in the highest occupied molecular orbital (HOMO), the degree of covalency (the degree of metal-sulfur $d-p$ interaction) and the covalent occupancy of the HOMO but also the nature of the HOMO itself must be considered. In the best catalysts the sulfide should have a HOMO filled with as many electrons as possible and be of $t_{2 g}$ symmetry instead of $e_{g}$. The degree of covalency and the covalent bond strength counterbalance each other. While the covalent bond strength decreases from the left to the right in the periodic table, the metal-sulfur orbital mixing increases, due to an increasing number of anti-bonding electrons present, weakening the covalent bond strength. In the case of the synergic pairs, MoM' $\mathrm{S}_{9}{ }^{n-}$ clusters were calculated varying the nature of the $3 d \mathrm{M}$ ' metal from $\mathrm{V}$ to $\mathrm{Zn}$. Both metals are octahedrally coordinated by six sulfur atoms, three of which are shared between the two metals. The main effect observed when varying M' through the first TM row series is a relative shift downward of the M' $3 d$ energy levels compared to Mo $4 d$ " $t_{2 g}$ " and " $e_{g}$ " levels. The Co and $\mathrm{Ni}$ " $t_{2 g}$ " orbitals lie well below the Mo orbitals while the higher set of $e$ orbitals are still at a higher energy level.

Since the theory was introduced many improvements have been made but the basic scheme remains the same. Many of the detailed objections have been corrected and less empirical approaches applied [31]. Another objection to the above approach is that it does not provide a specific geometric model and many calculations have proposed various geometrically specific models to make up this deficiency, however, it is a major conclusion of this paper as described further that the specific stabilized active catalysts have not yet been subjected to the DFT method.

\section{THE CATALYTICALLY STABLE STATES OF $\mathrm{MOS}_{2}$ BASED CATALYST}

A key aspect of this report is to distinguish between the catalyst precursor and the stabilized catalyst. Understanding the nature of the stabilized catalyst is essential before attempting calculations. The simple scheme that follows indicates that the "edge plane" chemistry of $\mathrm{MoS}_{2}$ changes after sulfidation and after stabilization in the catalytic environment.

$$
\begin{gathered}
\text { sulfidation } \Rightarrow \operatorname{MoS}_{2+x}(0<x<0.5) \\
\text { catalytic conditions } \Rightarrow \operatorname{MoS}_{2-x} \mathrm{C}_{y}(0<y<1)
\end{gathered}
$$

The values of $x$ and $y$ grow as the particle size decreases. A large amount of information exists for the sulfided precursors and much less for the stabilized catalyst state. The catalytic importance of the $\mathrm{MoS}_{2}$ "edge planes" is well


Figure 9

$\mathrm{MoS}_{2}$ Precursor and catalytically stabilized states: (a) presulfided in $\mathrm{H}_{2} \mathrm{~S}$, (b) after catalytic conditions.

established. What are the chemical states of these "edge plane sites"? The answer depends on the conditions under which the observations are made. For example, Chang and Chan [32] observed that after sulfiding $\mathrm{MoS}_{2}$ catalyst precursors disulfide bonds were observed using IR and Raman techniques. They observed that catalytically active, poorly crystalline $\mathrm{MoS}_{2}$ exhibit sharp infrared bands at 385 and $470 \mathrm{~cm}^{-1}$. However, broad bands at 287, 335, 373, and $522 \mathrm{~cm}^{-1}$ appear after $\mathrm{H}_{2} \mathrm{~S}$ treatment indicating the presence of polysulfide bands. The intensity of the IR peaks increased as the $\mathrm{MoS}_{2}$ edge area increased. This would lead to a composition that can be described as $\mathrm{MoS}_{2-x}(\mathrm{~S}-\mathrm{S})_{0.5 y}$. A simulation of this state is shown in Figure 9a . In this example, the hypothetical cluster would have the stoichiometry $\mathrm{MoS}_{1.88}(\mathrm{~S}-\mathrm{S})_{1.12}$. The polysulfide bonds could be placed in other locations, illustrating the complexity of defining the $\mathrm{MoS}_{2}$ catalytic edge planes.

Figure 9b ilustrates another hypothetical $\mathrm{MoS}_{2}$ cluster after the edge planes are stabilized in a catalytic hydrodesulfurization environment. In this case, the catalyst is sulfur deficient and contains carbon in a "carbide" environment. The stoichiometry in this case is $\mathrm{MoS}_{1.88} \mathrm{C}_{1.12}$. Although, the exact structure of the edge carbide is not known the carbiding of $\mathrm{MoS}_{2}$ edge plane is supported by synchrotron studies of catalysts stabilized in HDS conditions [33]. In this study, carbon edge X-ray absorption studies clearly indicated, through the measurement of Auger electrons emanating from the catalyst surface as a function of x-ray energy, that the surfaces of MoC and the stabilized $\mathrm{MoS}_{2}$ catalysts were identical. This is an example of the surface of a "working catalyst" and indicates that understanding of catalyst structure/function relations requires the study of such stabilized catalysts and that the study of precursors, though useful in understanding the chemistry of the catalytic material, is not sufficient for describing the active catalyst. In addition $\mathrm{MoS}_{2}$ becomes highly disordered in the catalytic environment thus introducing another level of complexity.

As described above, the reactivity of $\mathrm{MoS}_{2}$ based catalysts depends on disordered edge planes presenting themselves to the reactants in a catalytic environment. The edge planes are highly active, unlike the basal planes that are thought to be 
inert. The total activity depends on the number of these sites present in a stabilized catalytic environment. Basic studies have proven that the selectivity of unsupported $\mathrm{MoS}_{2}$ catalysts are affected by the stacking height of the $\mathrm{MoS}_{2}$ slabs in the Rim and Edge model proposed by Daage and Chianelli [34]. In such a model, the rim sites are active for hydrogenation reactions and $\mathrm{C}-\mathrm{S}$ bond rupture while edge sites are active only in C-S rupture. A freshly prepared active catalyst presents stacks of four to five slabs. Much of the HDS literature has attempted to rectify the "rim/edge" theory with selectivity studies done on commercial alumina supported catalysts. However, the original "rim/edge" theory did not include the promotion effect on selectivity and furthermore most studies have been done on commercial catalysts that are not stabilized in a catalytic environment. Recent studies show that when a commercial catalyst is stabilized in an operating catalytic environment, only single layers exist as described below [35]. This fact has been missed until recently and is a crucial concept for understanding and optimizing these catalysts. In addition, it has become necessary to reevaluate and understand the selectivity of promoted single layer commercial catalysts at a fundamental level.

Numerous techniques have been extensively used in an attempt to understand the structure of the catalyst active phase including HRTEM (high resolution transmission electron microscopy and XAS (X-ray absorption spectroscopy). However, the highly anisotropic layered stacked structure has limited the information that can be drawn from the catalytically stable state of an HDS catalyst. Furthermore, the interaction of the support with the active phase adds to the difficulty in determining catalyst dispersion. Perhaps one of the leading techniques used to average slab lengths and mean values for the stacking numbers is HRTEM. However, its ability to detect the $\mathrm{MoS}_{2}$ slabs strongly depends on how the slabs are bonded to the support [36]. Edge-bonded layers are clearly visible whereas thin flat slabs of $\mathrm{MoS}_{2}$ are simply missed. XAS measurements underestimate the dimensions along the basal plane because ordered sulfide particles are assumed in the fitting procedure while they are disordered and distorted in real catalysts [37]. Structural analysis of Xray diffraction patterns on the other hand, probes all orientations of the $\mathrm{MoS}_{2}$ slabs and gives an unbiased picture of the catalyst morphology.

In the recent study, mentioned above, by Perez de La Rosa et al. [35], three commercial $\mathrm{Co} / \mathrm{MoS}_{2} / \mathrm{Al}_{2} \mathrm{O}_{3}$ catalysts were analyzed using synchrotron radiation $\mathrm{X}$-ray diffraction. The catalysts differ by the length of time of use in a commercial reactor; the first run for one week, the second run for one month in a pilot plant, and the third run in an industrial plant for four years. The widths of the diffraction peaks were used to estimate the size of the lattice coherence normal to the diffraction vector. Liang et al. [38] have established a procedure for quantitatively determining the size of the $\mathrm{MoS}_{2}$ slabs from the analysis of the diffraction pattern of poorly crystalline



Figure 10

$\mathrm{MoS}_{2}$ single layers in stabilized commercial catalyst: diffraction: A - one week catalyst, B - one month catalyst, C - four year catalyst. From [34].

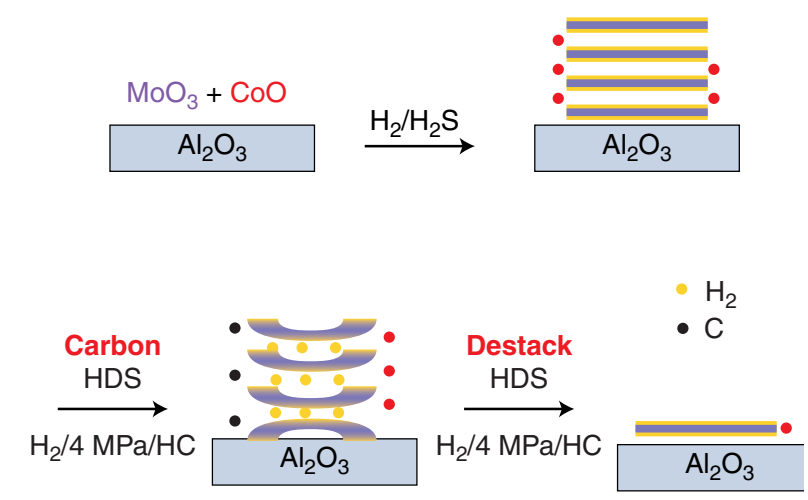

Figure 11

$\mathrm{MoS}_{2}$ catalyst stabilizing in a hydrogen/hydrocarbon environment.

$\mathrm{MoS}_{2}$. Following their procedure the (002) peak was used to determine the height and the (110) peak to determine the diameter of the $\mathrm{MoS}_{2}$ slab. The line broadening analysis was complemented by a full scattering model. The full scattering model evaluates the area of the (002) peak and the diffuse scattering area under the (002) peak to determine the fractions of stacked and unstacked layers. The relative proportions of stacked and unstacked layers were then directly obtained from the XRD data as seen in Figure 10. Their results were surprising and unexpected. After four years of industrial hydrotreating operations, the synchrotron scattering patterns of these catalysts show that they are completely de-stacked. The catalyst consists of single layers of $\mathrm{MoS}_{2}$ with a minor loss of activity. As the pressure increased from 5.5 MPa to 7.8 MPa a strong decrease in stacking was observed. Therefore, high 
pressure applied during the hydrotreating conditions was determined to be the main cause for the destacking effect observed in the spent commercial catalysts under industrial conditions. This result was also seen in freshly prepared catalyst run in DBT reported in the same paper.

A materials study with similar pressure-crystallization effects was reported by Peng et al. [39] where the slab stacking decreased with increasing pressure inside the reactor during the hydrothermal synthesis of $\mathrm{MoS}_{2}$ in an autoclave. The authors suggested that perhaps other experimental parameters of the HDS process, such as the hydrocarbon pressure or concentration could contribute to the destacking effect. The formation of multilayered stacks through van der Waals forces seems counterbalanced by the strong interaction of adsorbed hydrocarbon molecules that provide stability to single $\mathrm{MoS}_{2}$ layers. In retrospect, this point seems obvious in that if hydrogen intercalates at high pressure, then the layers would simply slide apart with time. This process is indicated schematically in Figure 11. This fact however, emphasizes the importance of studying stabilized catalyst to develop fundamental insight.

Finally, we note from the study of Perez de La Rosa et al. [35], that Co metal is present in the catalyst stabilized for four years. The HRTEM of a Co particle is shown in Figure 12. XRD studies indicated the presence of both $\mathrm{Co}_{9} \mathrm{~S}_{8}$ and $\mathrm{Co}$ metal as well. When the catalyst was activity tested in DBT at lower $\mathrm{H}_{2}$ pressure $\left(35 \mathrm{kPa}\right.$ vs. $78 \mathrm{kPa}$ ), more $\mathrm{Co}_{9} \mathrm{~S}_{8}$ appeared and no Co metal was detected. This result indicates that the

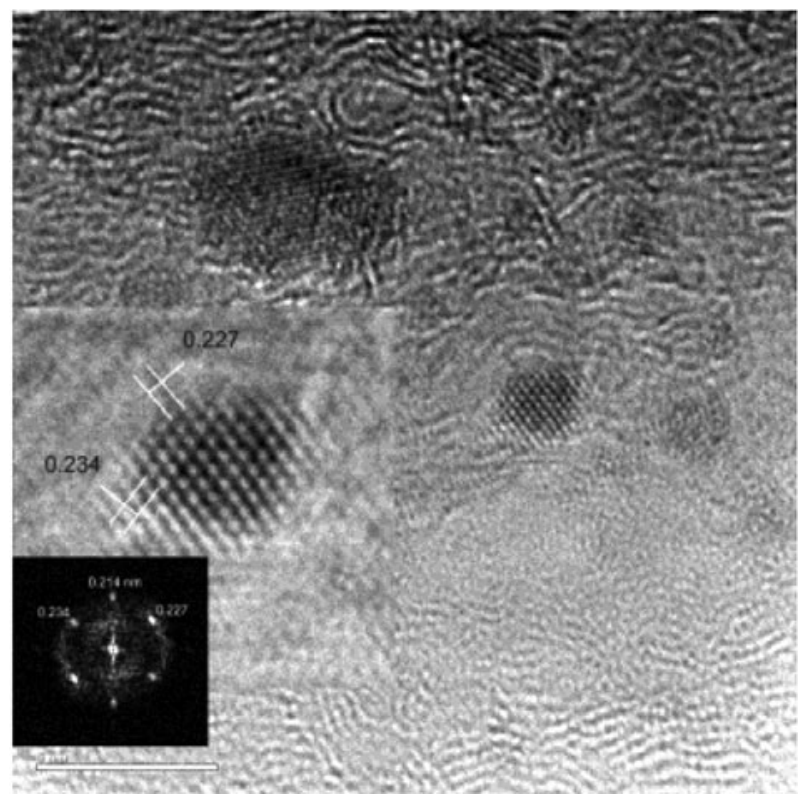

Figure 12

Co metal in stabilized, commercial $\mathrm{MoS}_{2}$ based catalyst (four years in VGO from [34]). stabilized state of the Co changes as a function of $\mathrm{H}_{2}$ pressure, sulfur concentration and temperature. This fact has been largely ignored in the literature and calls into question any specific theoretical model regarding Co promotion. Describing this phenomenon accurately also remains a challenge.

Schweiger et al. [40] have started to address this problem using DFT theoretical techniques and have concluded that the state of the promoter metal $(\mathrm{Co} / \mathrm{Ni})$ can be quite different depending on $\mathrm{H}_{2} / \mathrm{H}_{2} \mathrm{~S}$ ratio during catalytic processing. However, a complete picture will require the addition of the hydrocarbon phase in which the catalyst operates. This environment leads to the carbiding of the surface and the stabilized TMS.

\section{CONCLUSIONS}

Application of Sabatier's principle to the TMS catalytic materials has stood the test of time. The most important contribution of the application of Sabatier's principle has been its successful application to mixtures of TMS catalytic material, accurately predicting promotion and poisoning effects. Modern DFT improvements have refined the concept and predictions with increasing success. A detailed picture of the role of electronic structure in effecting the catalytic properties of the TMS has emerged.

More specific structural models of important TMS catalytic materials such as $\mathrm{MoS}_{2}$ have been hampered by the lack of knowledge of their stabilized catalytic state. In the case of $\mathrm{MoS}_{2}$ carbided edge planes exist in the stabilized state. At this writing no specific picture of the carbided edge planes has been presented. Thus, DFT calculations that describe sulfide edge planes are descriptions of catalytic precursors that are modified upon exposure to the catalytic environment. Similarly, recent studies have shown that the state of the Co in $\mathrm{MoS}_{2}$ industrial catalysts changes as a function of $\mathrm{H}_{2}$ pressure. Therefore, Co can exist in three states in an operating catalytic environment: Co associated with the $\mathrm{MoS}_{2}$ edge planes, $\mathrm{Co}_{9} \mathrm{~S}_{8}$ and Co. These facts are reminiscent of the early days of study in this field when very specific models held temporary prominence, and were then abandoned as contrary evidence emerged.

The emergence and application of DFT techniques has revolutionized the study of TMS catalytic materials and will continue to change the field. However, the technique must be applied with caution and a good dose of intuition. It is clear at this point in time the TMS catalytic materials must be viewed as dynamic catalytic system, in which the stabilized catalytic state is constantly changing as catalytic conditions change. Thus, a static picture of the active site does not accurately describe the catalyst. The ability of the TMS to constantly rearrange the bulk and surface states as the catalytic conditions change is the true measure of their catalytic properties and this in turn goes back to the fundamental properties of the $4 d$ and $5 d$ electrons in the system. 


\section{ACKNOWLEDGEMENTS}

This work was supported in part by grants from the U.S. Department of Energy "Gateway" Program, the Robert A. Welch Foundation, and the National Science Foundation. I would like to than Dr. Xiomara Carolina Kretschmer for a critical reading of the manuscript. I would particularly like to thank all my colleagues in France for years of encouragement and support: Marc Ledoux, Michelle Breysse, Michel Vrinat, Gilles Berhault, Pascal Raybaud, Slavik Kasztelan, and Hervé Toulhoat.

\section{REFERENCES}

1 Sabatier, P. (1966) Catalysis in Organic Chemistry, in Nobel Lectures in Chemistry 1901-1921, Malmström, B.G., Ed. (Chalmers University of Technology, Göteborg University), Elsevier Publishing Company, Amsterdam.

2 Bergius, F. (1966) Chemical Reactions Under High Pressure, in Nobel Lectures in Chemistry 1901-1921, Malmström, B.G., Ed. (Chalmers University of Technology, Göteborg University), Elsevier Publishing Company, Amsterdam.

3 Pier, M. (1949) Z. Elektrochem., 35, 291-299.

4 Weisser, O. and Landa, S. (1973) Sulphide Catalysts Their Properties and Applications, Pergamon Press, Oxford, New York.

5 Chianelli, R.R., Daage, M. and Ledoux, M.J. (1994) Fundamental studies of transition metal sulfide catalytic materials, Adv. Catal., 40, 177-232.

6 Sinfelt, J.H. (1983), Bimetallic Catalysts ; Discoveries, Concepts and Applications, John Wiley and sons, Inc., N.Y.C., N.Y.

7 Chianelli, R.R. and Dines, M.B. (1975) Inorg. Chem., 14, 2417.

8 Pecoraro, T.A. and Chianelli, R.R. (1981) J. Catal., 67, 429.

9 Ledoux, M.J. and Djellouli, B. (1989) J. Catal., 115, 580.

10 Eijsbouts, S., de Beer, V.J.H. and Prins, R. (1988) J. Catal., 109, 217.

11 Lacroix, M., Boutarfa, N., Guillard, C., Vrinat, M. and Breysse, M. (1989) J. Catal., 120, 473.

12 Tan, A. and Harris, S. (1998) Inorg. Chem., 37, 2215.

13] Vissers, J.P.R., Groot, C.K., van Oers, E.M., de Beer, V.J.H. and Prins, R. (1984) B. Soc. Chim. Belg., 93, 813.

14 Ledoux, M.J., Michaux, O., Agostini, G. and Pannisod, J. (1986) J. Catal., 102, 275.

15 Benard, J., Oudar, J., Barbouth, N., Margot, E. and Berthier, Y. (1979) Surf. Sci., 88, L35-L41.

16 Toulhoat, H., Raybaud, P., Kasztelan, S., Kresse, G. and Hafner, J. (1999) Catal. Today, 50, 629-636.
17 Raybaud, P., Kresse, G. Hafner, J. and Toulhoat, H. (1997) J. Phys.-Condens. Mat., 9, 11085.

18 Toulhoat, H. and Raybaud, P. (2003) J. Catal., 216, 63-72.

19 Topsøe, H., Clausen, B.S. and Massoth, F.E. (1996) in Catalysis, Science and Technology, vol. 11, Anderson, J.R. and Boudard, M., Eds., Springer-Verlag, Berlin.

20 Voorhoeve, R.J.H. (1976) J. Catal., 23, 243.

21 Farragher, A.L. and Cossee, P. (1973) in Proceedings, 5th International Congress on Catalysis, Palm Beach, 1972, Hightower, J.W., Ed., North-Holland, Amsterdam, 1291.

22 Topsøe, H., Clausen, B.S., Candia, R., Wivel C. and Morup, S. (1981) J. Catal., 68, 433.

23 Helveg, S., Lauritsen, J.V., Laegsgaard, E., Stensgaard, I., Nfrskov, J., Clausen, B.S., Topsfe, H. and Besenbacher, F. (2000) Phys. Rev. Lett., 84, 851.

24 Chianelli, R.R. and Berhault, G. (1999) Catal. Today, 53, 357-366.

25 Hagenbach, G., Courty, P. and Delmon, B. (1971) J. Catal., 23, 295.

26 Phillips, R.W. and Fote, A.A. (1976) J. Catal., 41, 168.

27 Chianelli, R.R., Pecoraro, T.A., Halbert, T.R., Pan, W.-H. and Stiefel, E.L. (1984) J. Catal., 86, 226.

28 Rayboud, P., Toulhoat, H. and Kasztelan, S. (2000) U.S. Patent 6, 149, 799.

29 Harris, S. and Chianelli, R.R. (1984) J. Catal., 86, 400.

30 Raybaud, P., Hafner, J., Kresse, G. and Toulhoat, H. (1997) J. Phys.-Condens. Mat., 911107.

31 Chianelli, R.R, Berhault, G., Raybaud, P., Kasztelan, S., Hafner, J. and Toulhoat, H. (2000), Appl. Catal. A-Gen., 227, 83-96.

32 Chang, C.H., Chan, S.S. (1981) J. Catal., 72, 139.

33 Berhault, G., Mehta, A., Pavel, A., Yang, J., Rendon, L., José-Yacamán, M., Cota-Araiza, L., Moller, A. and Chianelli, R.R. (2001) J. Catal., 198, 9.

34 Daage, M. and Chianelli, R.R. (1994) J. Catal., 149, 414.

35 Pérez De la Rosa, M., Texier S., Berhault, G., Camacho, A., José-Yacamán, M., Mehta, A., Fuentes, S., Montoya, J.A., Murrieta, F. and Chianelli R.R. (2004) J. Catal., 225, 288.

36 Eijsbouts, S. and VanLeerdam, G.C. (1995) B. Soc. Chim. Belg., 104, 347.

37 Shido, T. and Prins, R. (1998) J. Phys. Chem. B, 102, 8426.

38 Liang, K.S., Chianelli, R.R., Chien, F.Z. and Moss, S.C. (1986) J. Non-Cryst. Solids, 79, 251.

39 Peng, Y., Meng, Z., Zhong, C., Lu, J., Yu, W., Yang, Z. and Qian, Y. (2001) J. Solid State Chem., 159, 170.

40 Schweiger, H., Raybaud, P. and Toulhoat, H. (2002) J. Catal., 212, 33-38.

Final manuscript received in June 2006

Copyright $(0) 2006$ Institut français du pétrole

Permission to make digital or hard copies of part or all of this work for personal or classroom use is granted without fee provided that copies are not made or distributed for profit or commercial advantage and that copies bear this notice and the full citation on the first page. Copyrights for components of this work owned by others than IFP must be honored. Abstracting with credit is permitted. To copy otherwise, to republish, to post on servers, or to redistribute to lists, requires prior specific permission and/or a fee: Request permission from Documentation, Institut français du pétrole, fax. +33147527078 , or revueogst@ifp.fr. 